Dermatol Psychosom 2001;2:153-154

\section{GENERAL INFORMATION and APPLICATION FORM}

\section{Purposes}

The primary purpose of the European Society for Dermatology and Psychiatry is to provide a forum of European physicians and psychologists working in the field of psychodermatology, psychosomatic dermatology, and dermatopsychiatry. The continuing aims of the European Society for Dermatology and Psychiatry are to exchange information and ideas, to expand the contacts of those working in the disciplines of dermatology, psychiatry, and psychology, to improve scientific research in this area, and to recruit the expertise of new members. The ultimate aim, is to apply this knowledge to improve the quality of patient care.

Further purposes are:

* to stimulate interest in this field, particularly amongst European dermatologists, psychiatrists, psychologists, and other professionals with special interest in this area,

* to promote interdisciplinary research and education on dermatology, psychology and psychiatry in order to improve the knowledge, the management and the treatment of patients,

* to organize international congresses on dermatology, psychology and psychiatry,

* to inform and educate the medical profession at large and also the general public of recent developments in this field.

\section{Establishment}

The European Society for Dermatology and Psychiatry is a non-profit organization, legally established in 1993 in Vienna, according to the Austrian law.

\section{Executive Committee}

The Executive Committee of the Society consists of 11 members: the Chairman, the Secretary General, the Treasurer, and 8 Counselors.

Chairman:
Secretary General:
Treasurer:
Counselors:

Emiliano Panconesi

Italy

Leslie Millard

John de Korte

Christopher Bridgett

Sylvie Consoli

John Cotterill

Uwe Gieler

Francisco Grimalt

Michael Musalek

Françoise Poot

Klaus Taube
England

The Netherlands

England

France

England

Germany

Spain

Austria

Belgium

Germany

\title{
4. Journal
}

The official journal of the Society is: «Dermatology + Psychosomatics», International Journal for Dermatology in Psychosomatic Medicine, Psychiatry, Clinical Psychology and Public Health (Karger, Germany). The journal is published every three months.

Subscription is included in the membership fee.

\section{Congresses}

The Society organizes an international congress every two years. Moreover, it participates in other international congresses, such as the Congress of the European Academy of Dermatology and Venereology.

\section{Application for membership}

Physicians and psychologists, who are citizens of a European country, have graduated from University, and are working in the field of dermatology, psychology, or psychiatry are encouraged to apply for ordinary membership. Physicians and psychologists who are not citizens of a European country, are encouraged to apply for associate membership.

Students interested and working in the field of dermatology, psychology and psychiatry, as well as all interested professionals may apply for associate membership.

Applicants for membership shall forward a completed application form to the secretary. 


\section{APPLICATION FOR MEMBERSHIP}

Name: First

Profession

Date of Birth

Mailing address

Postal code

Country

Phone:

Country code Area code Number

Fax: Country code Area code Number

E-mail address

Name of referee 1:*

Name of referee 2:*

I hereby apply for membership of the European Society for Dermatology und Psychiatry.

I remit the membership fee of $€ 75$ to:

Postbank, Account Number 6934059, ESDaP - Amsterdam, The Netherlands**

Date:

Signature:

* According to the ESDaP rules for application it is necessary to have two referees, members of the ESDaP, who recommend the applicant to the ESDaP. On request, a membership list can be sent to you.

** Further instructions on payment: see below.

\section{INSTRUCTIONS ON PAYMENT}

Your membership fee should be paid to the Treasurer of the European Society for Dermatology and Psychiatry, Amsterdam, The Netherlands. There are three alternatives:

1. Remit an amount of $€ 75$ from your Bank Account to:

Postbank, Account number 6934059, Treasurer ESDaP, Amsterdam, the Netherlands.

2. Send any Bank Cheque of $€ 75$ directly to the Treasurer of the European Society for Dermatology and Psychiatry, J. de Korte: Academic Medical Center, P.O. Box 22700, 1100 DE Amsterdam, The Netherlands.

3. Send an Eurocheque of $€ 75$ directly to the Treasurer of the European Society for Dermatology and Psychiatry, J. de Korte: Academic Medical Center, P.O. Box 22700, 1100 DE Amsterdam, the Netherlands.

Credit cards and personal cheques cannot be accepted. 